\title{
EVOLUÇÃO DO ÍNDICE DE DESENVOLVIMENTO HUMANO - IDHM: UMA ANÁLISE A PARTIR DA DIMENSÃO DA EDUCAÇÃO NO MUNICÍPIO DE SINOP
}

\author{
Angelo Palmisano, Centro Universitário de Várzea Grande - UNIVAG \\ angelo.palmisano@univag.edu.br \\ Andrieli Caroline Lima, Centro Universitário de Várzea Grande - UNIVAG \\ andrieli@univag.edu.br
}

\section{RESUMO}

O objetivo desta pesquisa é analisar o comportamento do Índice de Desenvolvimento Humano Municipal - IDHM do município de Sinop, localizado ao norte do Estado de Mato Grosso, por meio da comparação da sua evolução ocorrida entre os anos de 1991, 2000 e 2010, tomando como base a dimensão Educação do indicador. Como metodologia desta pesquisa exploratória e de abordagem qualitativa, foram utilizadas fontes secundárias, mais especificamente foram realizadas consultas a documentos constantes nas bases de dados dos sistemas MEC/INEP, Plataforma Sucupira, CAPES, Atlas Brasil e IBGE. Os resultados obtidos apontam para uma melhora objetiva tanto no quesito quantitativo quanto no qualitativo, verificado no segmento educacional, que destaca o referido município no Estado e no país. Infere-se nesta análise que o processo educacional possui papel preponderante no desenvolvimento da região.

Palavras-chave: Desenvolvimento Humano; IDHM; Desenvolvimento Territorial e Local; Educação; Sinop.

Data de recebimento: $15 / 11 / 2020$

Data do aceite de publicação: 10/12/2020

Data da publicação: $30 / 12 / 2020$ 
EVOLUÇÃO DO ÍNDICE DE DESENVOLVIMENTO HUMANO - IDHM DE SINOP: UMA ANÁLISE A PARTIR DA DIMENSÃO DA EDUCAÇÃO NO MUNICÍPIO

\title{
EVOLUTION OF THE HUMAN DEVELOPMENT INDEX - IDHM: AN ANALYSIS FROM THE DIMENSION OF EDUCATION IN THE MUNICIPALITY OF SINOP
}

\author{
Angelo Palmisano, Centro Universitário de Várzea Grande - UNIVAG \\ angelo.palmisano@univag.edu.br \\ Andrieli Caroline Lima, Centro Universitário de Várzea Grande - UNIVAG \\ andrieli@univag.edu.br
}

\begin{abstract}
The objective of this research is to analyze the behavior of the Municipal Human Development Index - IDHM of the municipality of Sinop, located in the north of the State of Mato Grosso, by comparing its evolution between the years 1991, 2000 and 2010, taking based on the Education dimension of the indicator. As a methodology for this exploratory research and with a qualitative approach, secondary sources were used, more specifically, constant consultations were carried out on documents contained in the databases of the MEC / INEP, Plataforma Sucupira, CAPES, Atlas Brasil and IBGE systems. The results obtained point to an objective improvement in both the quantitative and qualitative aspects, verified in the educational segment, which highlights the aforementioned location in the State and in the country. It is inferred in this analysis that the educational process has a predominant role in the development of the region.
\end{abstract}

Keywords: Human Development; IDHM; Territorial and Local Development; Education; Sinop.

\section{INTRODUÇÃO}

Teorias de desenvolvimento regional e local têm sido utilizadas para estudos que permitam compreender melhor os fatores preditivos, os promotores e os detratores da melhoria da qualidade de vida dos humanos (BELLINGIERI, 2017), haja vista ser o desenvolvimento considerado um dos fatores que pode propiciar benefícios às pessoas, ao mesmo tempo em que tem sido um dos maiores desafios de todos os tempos do homo sapiens.

Mais recentemente e em nível internacional, Educação de Qualidade compõe o $4^{\circ}$ objetivo dentre os 17 Objetivos de Desenvolvimento Sustentável (ODS) estabelecidos pela ONU (2015), e conforme estudos de Avelar, Silva-Oliveira e Pereira (2019) o tema recebe destaque também no Brasil. A pesquisa dessas autoras revisou sistematicamente a literatura sobre Educação em relação à implementação dos ODS e identificou padrões bibliométricos e evidências, tendo apresentado redes de coautoria, periódicos, instituições de ensino superior (IES) e países mais influentes nessa dimensão educacional, sobretudo no que se refere à responsabilidade social.

Ainda considerando-se o Brasil, o item III - "educação e qualificação profissional", do artigo $7^{\circ}$ do Decreto $n^{\circ} .9 .810$ de 30 de maio de 2019 estabelece prioridade ao quesito Educação, em legislação que define a Política Nacional de Desenvolvimento Regional. Assim, tanto 


\section{EVOLUÇÃO DO ÍNDICE DE DESENVOLVIMENTO HUMANO - IDHM DE SINOP: UMA ANÁLISE A PARTIR DA DIMENSÃO DA EDUCAÇÃO NO MUNICÍPIO}

internacionalmente, quanto no âmbito nacional, comprova-se a estreita relação entre Educação e desenvolvimento.

Santos, A. et al. (2020) publicaram pesquisa sobre o cenário das Instituições de Ensino Superior (IES), especificamente as de capital aberto atuantes no Brasil, dada a amplitude com que tais instituições atuam no País, e demonstraram as contribuições dessas organizações em relação ao número elevado de alunos, mas concluíram que isso nem sempre está relacionado à qualidade da Educação ofertada.

Para a mensuração do desenvolvimento humano, foi criado em 1990 o Índice de Desenvolvimento Humano (IDH), pelos economistas idealizadores Mahbub ul Haq e Amartya Sen (PNUD, 2103), que desde então foi adotado como medida para se avaliar uma nação sob uma ótica mais abrangente que a observação meramente econômica. O IDH considera três dimensões, quais sejam:

a) Longevidade: a melhoria do desenvolvimento humano pode permitir que as pessoas evitem a morte prematura, especialmente a partir de acesso à saúde de qualidade;

b) Educação: considerando-se ser o conhecimento fundamental para a prática da liberdade individual e da autonomia;

c) Renda: entendida como uma forma pela qual as pessoas conseguem garantir o alcance de suas necessidades básicas.

Para fins desta pesquisa, optou-se por analisar de forma mais aprofundada a dimensão Educação.

No Brasil, utiliza-se também o Índice de Desenvolvimento Humano Municipal (IDHM) para que se possa observar aspectos específicos de cada município, até porque o País, com suas dimensões continentais, apresenta enormes diferenças regionais, seja sob o aspecto geográfico, topográfico, climático, ambiental, econômico, cultural e inclusive educacional. Nesse caso, a longevidade é medida pela expectativa de vida ao nascer, mostrando assim o número médio de anos que as pessoas viveriam a partir do nascimento, se mantidos iguais padrões de mortalidade observados no ano de referência. Por sua vez, a dimensão renda é medida pela renda municipal média per capita. Em ambos os casos os cálculos são realizados a partir dos dados dos Censos Demográficos do Instituto Brasileiro de Geografia e Estatística (IBGE). Para a dimensão Educação o cálculo considera outras variáveis que serão detalhadas no item 4 deste texto. Faz-se, então a média geométrica das três dimensões para se chegar ao IDHM.

Sendo assim, em termos de delimitação do estudo, elegeu-se estudar a dimensão Educação do IDHM, por ser a mais complexa, em apenas um município, tendo sido escolhido o de Sinop, localizado no Estado de Mato Grosso. Esse município foi escolhido por apresentar importantes avanços em seu desenvolvimento ao logo do tempo, como se verá no item 4 deste estudo.

O problema estudado se caracteriza pela indagação sobre quais os fatores responsáveis pela evolução na dimensão da Educação daquele índice, uma vez que foi o indicador que apresentou maior crescimento no período estudado. Assim, a finalidade desta pesquisa é analisar a evolução no IDHM do município de Sinop, ocorrida entre as mensurações de 1991, quando foi realizado o primeiro IDHM do País, 2000, quando da segunda mensuração e 2010, sendo este o ano da última divulgação realizada até o encerramento desta pesquisa. 


\section{EVOLUÇÃO DO ÍNDICE DE DESENVOLVIMENTO HUMANO - IDHM DE SINOP: UMA ANÁLISE A PARTIR DA DIMENSÃO DA EDUCAÇÃO NO MUNICÍPIO}

O objetivo geral desta pesquisa é analisar o comportamento do IDHM do município de Sinop, localizado ao norte do Estado de Mato Grosso, por meio da comparação da sua evolução ocorrida entre os anos de 1991, 2000 e 2010, tomando como base a dimensão Educação daquele indicador nas series históricas disponíveis no ranking Atlas Brasil (2020).

Pretende-se demonstrar a importância da utilização de indicadores nacionais no País, consolidados em diversas publicações científicas (SANTOS, I. et al., 2020), sobretudo e mais especificamente o IDHM, identificando no município de Sinop os fatores responsáveis pelo seu desenvolvimento, em especial aqueles que se referem a Educação, em todos os níveis.

O objetivo específico é identificar no comportamento do indicador Educação no IDHM de Sinop nos anos de 1991, 2000 e 2010, os fatores determinantes de sua evolução.

O estudo se justifica pela relevância do IDHM para que se possa compreender fatores de desenvolvimento local e regional e, dessa forma, nortear gestores públicos nas tomadas de decisões. Dentre os indicadores que compõem o IDHM, de modo específico, analisa-se aqui o indicador Educação e sua contribuição nesse contexto.

A proposta metodológica do cálculo do IDHM na dimensão Educação, considera os seguintes Pesos das variáveis: Escolaridade da população adulta - Peso 1; Fluxo escolar da população jovem - Peso 2. Considera ainda métricas utilizadas no cálculo IDH Global, objetivando assim the atribuir maior significado.

A Educação Básica brasileira está estruturada em três etapas relacionadas à idade dos alunos: Educação Infantil (0 a 5 anos), Ensino Fundamental (6 a 14 anos) e Ensino Médio (15 a 17 anos) em nove séries no Ensino Fundamental e três séries que compõem o Ensino Médio. É avaliada por meio do Sistema de Avaliação da Educação Básica (SAEB) composto por três avaliações externas: a) Avaliação Nacional da Educação Básica - ANEB; b) Avaliação Nacional do Rendimento Escolar - ANRESC; c) Avaliação Nacional da Alfabetização - ANA. INEP (2015).

Objetivando integrar esses sistemas de avaliação por meio da utilização das informações que cada um deles é capaz de produzir, o INEP criou em 2007 o Índice de Desenvolvimento da Educação Básica (IDEB), que objetiva reunir em um indicador dois conceitos importantes para a qualidade da educação básica: o fluxo escolar e as médias de desempenho nas avaliações. Esse indicador é calculado a partir dos dados sobre aprovação escolar, obtidos no Censo Escolar e nas médias de desempenho nas avaliações do Inep obtidas no SAEB para as unidades da federação e para o país, e na Avaliação Nacional do Rendimento Escolar - ANRESC (Prova Brasil) para os municípios. INEP (2015).

O IDEB representa um indicador calculado de zero a dez, a partir da mensuração da proficiência em Língua Portuguesa e Matemática. O Plano Nacional de Educação - PNE 20142024 estabelece, como meta, que em 2021 o IDEB do Brasil para os anos iniciais do Ensino Fundamental seja 6,0 (seis) - média que corresponde a um sistema educacional de qualidade comparável a dos países desenvolvidos. O INEP estabeleceu as metas tomando por base a média dos países da OCDE. (INEP, 2020). 


\section{EVOLUÇÃO DO ÍNDICE DE DESENVOLVIMENTO HUMANO - IDHM DE SINOP: UMA ANÁLISE A PARTIR DA DIMENSÃO DA EDUCAÇÃO NO MUNICÍPIO}

Este artigo é composto por esta Introdução, seguido de Referencial Teórico, apresentado no item 2, da Metodologia descrita no item 3, da Análise de Dados e Discussão no item 4 e, na sequência, das Conclusões e Recomendações, seguido das Referências.

\section{REFERENCIAL TEÓRICO}

Este referencial teórico apresenta as bases conceituais que possibilitaram a compreensão do contexto e a análise do objeto estudado. Faz-se inicialmente um breve histórico sobre o município de Sinop e em seguida apresenta-se conceitualmente o IDHM.

\subsection{Breve história de Sinop e sua caracterização atual}

A cidade de Sinop surgiu como resultado da política de ocupação da Amazônia Legal Brasileira, desenvolvida pelo Governo Federal na década de 1970, por meio de projetos de colonização. A colonizadora da cidade, Sociedade Imobiliária Noroeste do Paraná, deu origem ao seu nome por meio da utilização de suas letras iniciais. A fundação de Sinop ocorreu em 14 de setembro de 1974, tendo sido elevada à categoria de Distrito em 1976 e em 1979 alcançou a sua autonomia política se tornando um município. Contava com uma área de $48.678 \mathrm{~km}^{2} \mathrm{e}$ passaram a fazer parte de Sinop os distritos de Vera, Santa Carmem, Claudia e Marcelândia (SINOP, 2020).

Estrategicamente localizado às margens da rodovia BR 163, por onde transitam riquezas do norte mato-grossense, interliga-se ao Estado do Pará. O município de Sinop fica a aproximadamente $500 \mathrm{~km}$ de Cuiabá, capital do Estado.

A partir das colonizações surgiram pequenas cidades e vilas, capazes de mudar a configuração territorial da região, dando início ao processo de urbanização do Norte MatoGrossense. Entre essas cidades o município de Sinop foi um dos primeiros. A inserção de núcleos urbanos se constituiu em pontos de centralização para atender as regiões a serem colonizadas. Esse fenômeno caracterizou a colonização de Mato Grosso nas décadas de 1970 e 1980. Esses núcleos centralizavam atividades econômicas, sociais e administrativas da região em emergente urbanização. Com o crescimento urbano resultante da chegada de nova população, novas ruas, avenidas e bairros foram criados, contribuindo para o aumento da comercialização dos lotes urbanos (SOUZA, 2017).

De acordo com Ravache (2013) o próprio traçado das rodovias que cortariam a região foi um instrumento de mapeamento, as regiões onde estavam os traçados das novas rodovias ficaram destinadas ao fomento desse desenvolvimento econômico planejado durante o período de colonização da região amazônica. Os poucos municípios existentes e suas baixas densidades demográficas, contribuíram significativamente para a urbanização do norte de Mato Grosso no final da década de 1970. Com a pressão da divisão do Estado, ocorrida em 1977, foi criada uma urgência para ocupação dos projetos de colonização instalados e emancipação daqueles consolidados.

A Figura 1 apresenta um mapa de localização do município de Sinop no Estado de Mato Grosso e a localização deste no País.

Figura 1 - Localização do município de Sinop 


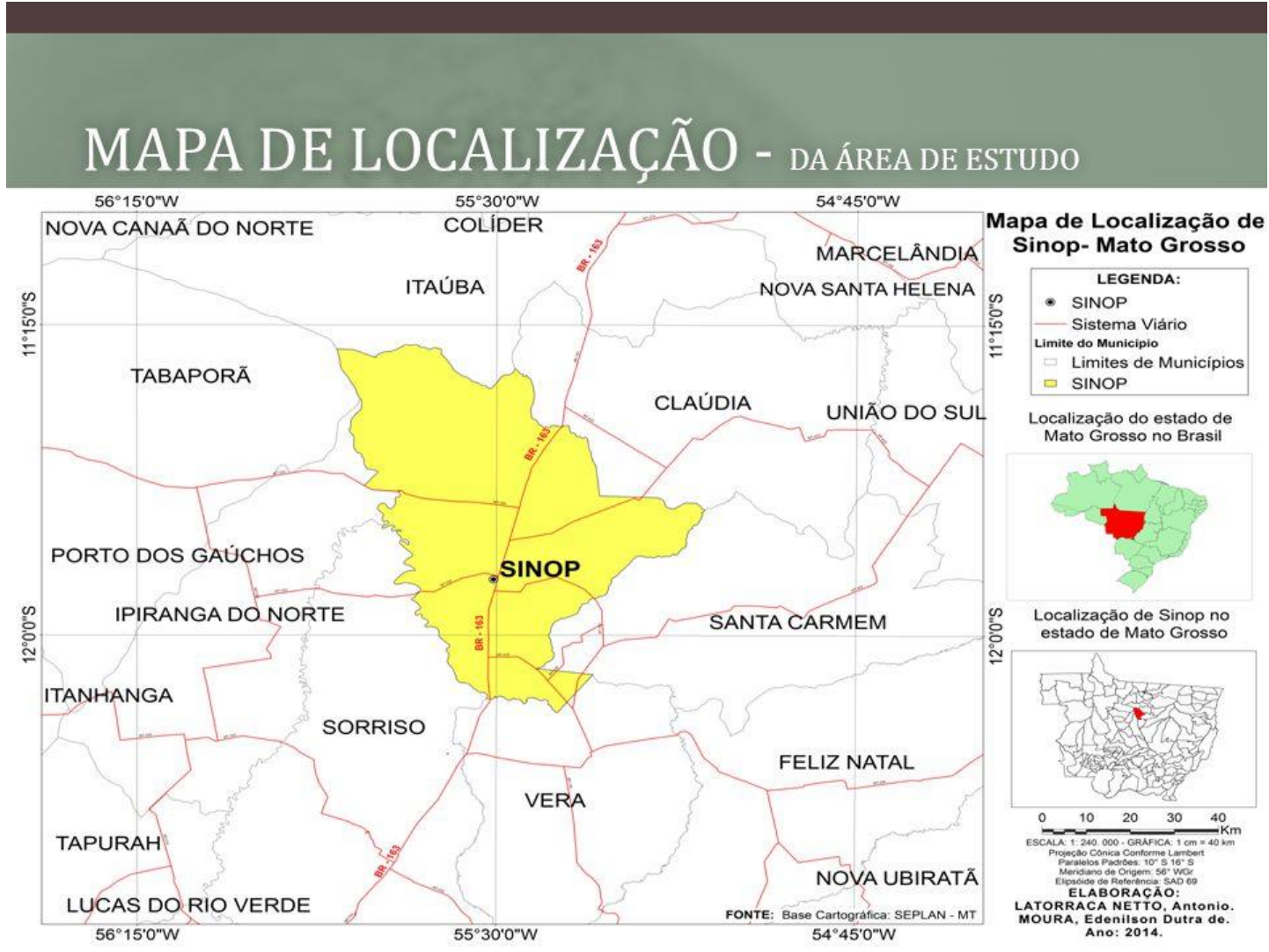

Fonte: Latorraca Netto e Moura (2014).

Apresentada a localização geográfica de Sinop, passa-se ao item 2.2, que trata da relevância do IDHM para estudos sobre desenvolvimento humano, utilizado tanto para análise macro no País, quanto para análises municipais, mais localizadas.

\subsection{O Índice de Desenvolvimento Humano - IDHM}

Diversas teorias de desenvolvimento local e regional têm sido utilizadas (BELLINGIERI, 2017) e todas elas envolvem a questão da Educação como um dos pontos cruciais para que haja desenvolvimento.

Melati e Janissek-Muniz (2020) mencionam que governo inteligente promove políticas públicas inclusivas, sob a ótica de uma análise de dimensões na perspectiva de gestores públicos, dentre as quais a Educação se destaca. Nesse sentido, Giovanini (2020) contribui ao afirmar que há estreita relação entre a governança pública e a economia compartilhada, aplicadas à educação são também relevantes para o desenvolvimento.

A plataforma Atlas do Desenvolvimento Humano no Brasil disponibiliza diversas informações estatísticas sobre o desenvolvimento humano no País que evidenciam características e desigualdades sociais existentes.

O Atlas do Desenvolvimento Humano no Brasil é resultado da parceria entre o Programa das Nações Unidas para o Desenvolvimento (PNUD), o Instituto de Pesquisa Econômica Aplicada (IPEA) e a Fundação João Pinheiro (FJP). Concebido com a finalidade de apresentar o Índice de Desenvolvimento Humano Municipal (IDHM), o Atlas hoje disponibiliza, além do índice, mais de 330 indicadores que percorrem temas como saúde, educação, renda e trabalho, habitação, vulnerabilidade social, meio ambiente e participação política, para os 5.570 municípios, cinco 


\title{
EVOLUÇÃO DO ÍNDICE DE DESENVOLVIMENTO HUMANO - IDHM DE SINOP: UMA ANÁLISE A PARTIR DA DIMENSÃO DA EDUCAÇÃO NO MUNICÍPIO
}

macrorregiões, 27 Unidades da Federação (UFs), 21 regiões metropolitanas (RMs), três regiões integradas de desenvolvimento (RIDEs) e aproximadamente 17.000 unidades de desenvolvimento humano (UDHs) ou "bairros", sendo o último as menores territorialidades brasileiras que dialogam diretamente com a realidade do cidadão (ATLASBR, 2020).

Ainda em relação ao Desenvolvimento Humano, considerado por SEN (2000) como fator relacionado à liberdade, envolvendo capacidades dos seres humanos, o que inclui participação ativa nas decisões políticas que influenciam a própria qualidade de vida das pessoas.

\begin{abstract}
A abordagem do desenvolvimento humano coloca as pessoas no centro da análise do bem-estar, perspectiva oposta ao que sugere a ideia de desenvolvimento ancorada no crescimento econômico, redefinindo a maneira como pensamos e lidamos com o desenvolvimento em diferentes escalas territoriais. A popularização desta abordagem se deu com a criação e adoção do Índice de Desenvolvimento Humano (IDH) como medida do grau de desenvolvimento humano de um país, em alternativa ao Produto Interno Bruto (PIB), que à época era a principal medida de desenvolvimento (ATLASBR, 2020).

O crescimento econômico de uma sociedade, de forma isolada, não se traduz automaticamente em qualidade de vida e, muitas vezes, o que se observa é um reforço das desigualdades. É preciso que este crescimento seja entendido como parte do processo de expansão das liberdades e transformado em conquistas concretas para as pessoas: crianças mais saudáveis, educação universal e de qualidade, ampliação da participação política dos cidadãos, preservação ambiental, equilíbrio da renda e oportunidades para todas as pessoas, maior liberdade de expressão, entre outras (ATLASBR, 2020).
\end{abstract}

Embora aqui não se pretendeu detalhar as questões metodológicas que compõem a elaboração do IDHM, vale lembrar as premissas adotadas pela organização que o elabora: Atlas Brasil, assim como os dados que são considerados na sua composição.

\begin{abstract}
O IDH é uma medida criada para enfatizar que as pessoas e o desenvolvimento de suas capacidades devem estar no centro das decisões ao avaliar o desenvolvimento de um país.

O IDHM brasileiro é composto pelas mesmas três dimensões do IDH Global longevidade, educação e renda - mas vai além: adequa a metodologia global ao contexto brasileiro e à disponibilidade de indicadores nacionais. Embora meçam os mesmos fenômenos, os indicadores levados em conta no IDHM são mais adequados para avaliar o desenvolvimento dos municípios e regiões metropolitanas brasileiras. Portanto, resultados no IDH Global não são comparáveis com o IDHM nacional.

O Atlas do Desenvolvimento Humano no Brasil disponibiliza ainda, além do IDHM, mais de 330 indicadores socioeconômicos que permitem qualificar e ampliar a análise do desenvolvimento humano nos municípios e regiões metropolitanas do país (ATLASBR, 2020).
\end{abstract}

O IDHM classifica os 5.570 municípios brasileiros a partir das dimensões de Renda, Longevidade e Educação, por meio de um número que varia entre 0 e 1. Quanto mais próximo de 1 , maior o desenvolvimento humano de um município.

As faixas de Desenvolvimento Humano Municipal estão constituídas com as seguintes escalas e conceitos a elas atribuídos, conforme Quadro 1.

Quadro 1 - Valores do IDHM e seus Conceitos

\begin{tabular}{l|l} 
Valores do IDHM & Conceitos
\end{tabular}


EVOLUÇÃO DO ÍNDICE DE DESENVOLVIMENTO HUMANO - IDHM DE SINOP: UMA ANÁLISE A PARTIR DA DIMENSÃO DA EDUCAÇÃO NO MUNICÍPIO

\begin{tabular}{|c|c|}
\hline $0,0-0,499$ & Muito Baixo \\
\hline $0,500-0,599$ & Baixo \\
\hline $0,600-0,699$ & Médio \\
\hline $0,700-0,799$ & Alto \\
\hline $0,800-1,0$ & Muito Alto \\
\hline
\end{tabular}

Fonte: ATLASBR (2020).

Conforme mencionado, o IDHM é mensurado a partir de três dimensões: Renda; Longevidade; e Educação, cujas definições são apresentadas no Quadro 2.

Quadro 2 - Dimensões avaliadas no IDHM

\begin{tabular}{|c|l|}
\hline $\begin{array}{c}\text { RENDA } \\
\text { (Padrão de vida) }\end{array}$ & $\begin{array}{l}\text { A renda é essencial para acessarmos necessidades básicas como água, comida e abrigo, } \\
\text { mas também para podermos transcender essas necessidades rumo a uma vida de escolhas } \\
\text { genuínas e exercício de liberdades. }\end{array}$ \\
\hline $\begin{array}{c}\text { LONGEVIDADE } \\
\text { (Vida longa e } \\
\text { saudável) }\end{array}$ & $\begin{array}{l}\text { Ter uma vida longa e saudável é fundamental para a vida plena. A promoção do } \\
\text { desenvolvimento humano requer a garantia de um ambiente saudável, com acesso à saúde } \\
\text { de qualidade, para que as pessoas possam atingir o padrão mais elevado possível de saúde } \\
\text { física e mental }\end{array}$ \\
\hline $\begin{array}{c}\text { EDUCAÇÃO } \\
\text { (Acesso ao } \\
\text { conhecimento) }\end{array}$ & $\begin{array}{l}\text { O acesso ao conhecimento é um determinante crítico para o bem-estar, essencial para o } \\
\text { exercício das liberdades individuais e da autonomia. A educação é fundamental para } \\
\text { expandir as habilidades das pessoas para que elas possam decidir sobre seu futuro. } \\
\text { Educação constrói confiança, confere dignidade e amplia os horizontes e as perspectivas } \\
\text { de vida }\end{array}$ \\
\hline
\end{tabular}

Fonte: ATLASBR (2020).

Esta pesquisa está centrada na análise da dimensão Educação do IDHM. A escolha da análise sob a ótica da Educação também baseada na crença que representa elemento fundamental para o desenvolvimento humano em diversas faixas etárias.

\begin{abstract}
A Dimensão Educação (acesso ao conhecimento) do IDHM é medida por meio de indicadores da escolaridade da população adulta e indicadores do fluxo escolar da população jovem. A escolaridade da população adulta é medida pelo percentual da população de 18 anos ou mais de idade com o ensino fundamental completo, enquanto o fluxo escolar da população jovem é medido pela média aritmética: do percentual de crianças de 5 a 6 anos frequentando a escola; do percentual de jovens de 11 a 13 anos frequentando os anos finais do ensino fundamental regular; do percentual de jovens de 15 a 17 anos com ensino fundamental completo; e do percentual de jovens de 18 a 20 anos com ensino médio completo. Estes cinco indicadores são obtidos a partir do Censo Demográfico e da Pesquisa Nacional por Amostra de Domicílio - PNAD Contínua do IBGE (ATLASBR, 2020).
\end{abstract}

A Declaração Mundial sobre Educação para Todos, resultante da Conferência Mundial sobre Educação para Todos, realizada em Jomtien, Tailândia, de 5 a 9 de março de 1990 já apresenta esta condição "a educação pode contribuir para conquistar um mundo mais seguro, mais sadio, mais próspero e ambientalmente mais puro, que, ao mesmo tempo, favoreça o progresso social, econômico e cultural, a tolerância e a cooperação internacional" (WORLD CONFERENCE ON EDUCATION FOR ALL, 1990).

Dos diversos requisitos apresentados como artigos naquela declaração, destaca-se o artigo de número 8 que aponta para necessidade de ações articuladas.

ARTIGO 8 DESENVOLVER UMA POLÍTICA CONTEXTUALIZADA DE APOIO 1. Políticas de apoio nos setores social, cultural e econômico são necessárias à concretização da plena provisão e utilização da educação básica para a promoção individual e social. A educação básica para todos depende de um compromisso 


\title{
EVOLUÇÃO DO ÍNDICE DE DESENVOLVIMENTO HUMANO - IDHM DE SINOP: UMA ANÁLISE A PARTIR DA DIMENSÃO DA EDUCAÇÃO NO MUNICÍPIO
}

\begin{abstract}
político e de uma vontade política, respaldados por medidas fiscais adequadas e ratificados por reformas na política educacional e pelo fortalecimento institucional. Uma política adequada em matéria de economia, comércio, trabalho, emprego e saúde incentiva o educando e contribui para o desenvolvimento da sociedade (WORLD CONFERENCE ON EDUCATION FOR ALL, 1990).
\end{abstract}

O Atlas Brasil apresenta outros indicadores além dos cinco que compõem o IDHM Educação: analfabetismo; grau de escolaridade (fundamental completo, médio completo, superior completo); e frequência escolar (frequência bruta, líquida, atraso escolar).

O Atlas apresenta ainda o indicador Expectativa de anos de estudo, uma adaptação metodológica da métrica usada no IDH Global, considerando 12 anos como máximo de anos de estudos da Educação Formal (Ensino Básico), fazendo ajuste nos valores para considerar a repetência. Sendo assim, considera apenas a adequação da frequência escolar até os 18 anos de idade. Idealmente, considerando-se que todas as pessoas ingressam aos 6 anos no Ensino Fundamental e não há repetência ou evasão no Ensino Básico, esse indicador consideraria 12 anos (ATLASBR, 2020).

Ainda sob o viés do referencial teórico e justificando a escolha da proposta metodológica relacionada ao IDHM, cabe mencionar que partir do ano de 2020, a CAPES com o objetivo de beneficiar municípios menos desenvolvidos e buscando reduzir assimetrias no Sistema Nacional de Pós-Graduação (SNPG) incluiu novas faixas de classificação quanto ao IDHM da localidade onde é ofertado o curso de pós-graduação no modelo de concessão de Bolsas de Estudo.

\footnotetext{
O modelo continua o mesmo. Apenas ajustes foram feitos para reduzir assimetrias no Sistema Nacional de Pós-Graduação (SNPG), o que beneficia municípios menos desenvolvidos. Foram incluídas novas faixas de classificação quanto ao IDHM da localidade onde é ofertado o curso de pós-graduação...Para gerar impacto social e econômico nos municípios menos desenvolvidos do País onde são ofertados cursos de mestrado e doutorado, a concessão de bolsas também passa a levar em conta o Índice de Desenvolvimento Humano Municipal (IDHM). Com isso, por exemplo, um curso localizado em cidade de IDHM mais baixo terá até duas vezes o número de bolsas que um curso semelhante ofertado em um município de IDHM mais alto. O modelo, que será implementado de forma gradativa, prevê que o número de benefícios a ser concedido para cada curso será obtido pelo resultado da multiplicação de valores de referência de concessão de bolsas por pesos associados ao IDHM e à titulação média de estudantes (CAPES, 2020).
}

Evidencia-se assim a forma sistêmica de avaliação e análise da dimensão Educação desde anos iniciais até a Educação Continuada, que abrange a pós-graduação stricto sensu.

A partir deste Referencial Teórico que deu sustentação para este estudo, passa-se a apresentar a Metodologia utilizada nesta pesquisa.

\section{METODOLOGIA}

Sendo o objeto de análise os indicadores da dimensão Educação do IDHM do município de Sinop (MT), para a realização desta pesquisa entendeu-se como mais adequada a utilização de abordagem qualitativa (CRESWELL, 2014), que permite a compreensão ampla do fenômeno estudado (TRIVIÑOS, 1987; FLIK, 2008). 


\section{EVOLUÇÃO DO ÍNDICE DE DESENVOLVIMENTO HUMANO - IDHM DE SINOP: UMA ANÁLISE A PARTIR DA DIMENSÃO DA EDUCAÇÃO NO MUNICÍPIO}

Esta pesquisa é do tipo exploratória, realizada por meio de técnica de levantamento bibliográfico e de dados secundários provenientes de pesquisa documental.

Procedeu-se, então, a coleta de dados no período de junho a setembro de 2020 junto aos documentos publicados pelos órgãos oficiais, quais sejam: IBGE, INEP, INEPDATA, CAPES, EMEC, ATLASBR, PLATAFORMA SUCUPIRA.

Os dados foram analisados por meio de estatística descritiva, utilizando-se planilha Excel. A observação cuidadosa dos pesquisadores foi essencial para que se pudesse manter o rigor necessário na coleta e na análise dos dados.

\section{ANÁLISE DE DADOS}

Este item apresenta inicialmente a caracterização do município de Sinop e, na sequência, a análise dos dados levantados na pesquisa, quais sejam as relacionadas à dimensão Educação no IDHM desse município.

\subsection{Caracterização de Sinop}

O Quadro 3 apresenta a caracterização de Sinop quanto a População, Educação, Trabalho e Renda, Território e Ambiente e apresenta os principais números do município em relação esses quesitos.

Quadro 3 - Caracterização de Sinop quanto a População, Educação, Trabalho e Renda, Território e Ambiente

\begin{tabular}{|l|c|}
\hline \multicolumn{2}{|c|}{ POPULAÇÃO } \\
\hline População no último censo [2010] & 113.099 \\
\hline Densidade demográfica [2010] & 28,69 hab/km² \\
\hline População atual estimada [2020] & 146.005 \\
\hline \multicolumn{2}{|c|}{ EDUÇÃO } \\
\hline Taxa de escolarização de 6 a 14 anos de idade [2010] & $98 \%$ \\
\hline IDEB - Anos iniciais do ensino fundamental (Rede pública) [2017] & 5,8 \\
\hline IDEB - Anos finais do ensino fundamental (Rede pública) [2017] & 5,0 \\
\hline Matrículas no ensino fundamental [2018] & 20.857 matrículas \\
\hline Matrículas no ensino médio [2018] & 5.760 matrículas \\
\hline Docentes no ensino fundamental [2018] & 972 docentes \\
\hline Docentes no ensino médio [2018] & 366 docentes \\
\hline Número de estabelecimentos de ensino fundamental [2018] & 43 escolas \\
\hline Número de estabelecimentos de ensino médio [2018] & 16 escolas \\
\hline \multicolumn{1}{|c|}{ TRABHO E RENDIMENTO } \\
\hline de até 1/2 salário mínimo [2010]
\end{tabular}


EVOLUÇÃO DO ÍNDICE DE DESENVOLVIMENTO HUMANO - IDHM DE SINOP: UMA ANÁLISE A PARTIR DA DIMENSÃO DA EDUCAÇÃO NO MUNICÍPIO

\begin{tabular}{|l|c|} 
Área da unidade territorial [2020] & $3.990,870 \mathrm{~km}^{2}$ \\
\hline Esgotamento sanitário adequado [2010] & $10,8 \%$ \\
\hline Arborização de vias públicas [2010] & $84,6 \%$ \\
\hline Urbanização de vias públicas [2010] & $30,6 \%$ \\
\hline Bioma [2019] & Amazônia \\
\hline
\end{tabular}

Fonte: IBGE (2020).

Registre-se que em relação à população, entre 2010 e a projeção de 2020, pode-se verificar a ocorrência de um crescimento de $29,1 \%$ em Sinop, enquanto no Estado de Mato Grosso esse crescimento foi de 16,2\% e na capital Cuiabá de 12,2\%, conforme dados apresentados pelo IBGE em seu painel de Cidades (IBGE, 2020). Cabe mencionar ainda que o crescimento da população entre os anos de 2000 e 2010 foi de 51,1\% de acordo com IBGE (2020).

Outro dado que positivamente merece destaque está relacionado a Taxa de escolarização de 6 a 14 anos de idade em 2010, que foi de 98\%, representando que quase a totalidade da população nesta faixa etária encontra-se matriculada na escola, naturalmente o desejável é que esse percentual fosse de $100 \%$.

Cabe ainda menção a nota de Sinop no IDEB - Anos Iniciais do Ensino Fundamental (Rede pública, 2017) que foi 5,8, enquanto essa nota em Cuiabá, capital do Estado no mesmo período foi 5,6 e no Estado de 5,7 apontando para um melhor desempenho, assim como ocorreu também com a nota do IDEB - Anos Finais do Ensino Fundamental (Rede pública, 2017) que foi 5,0, enquanto a de Cuiabá foi 4,5 e a do Estado de 4,7 (IBGE, 2020). Chama a atenção o melhor desempenho no Ensino Fundamental atingido pelo município de SINOP, inclusive quando comparado ao desempenho médio no Estado.

\subsection{Análise do IDHM de Sinop nos anos de 1991, 2000 e 2010}

A Tabela 1 apresenta os dados referentes ao IDHM de Sinop, com os valores nos anos de 1991, 2000 e 2010, possibilitando sua análise em relação ao Ranking Brasil e ao do Estado de Mato Grosso.

Tabela 1 - Ranking IDHM Brasil, Mato Grosso e Sinop nos anos de 1991, 2000 e 2010

\begin{tabular}{c|c|c|c|c|c|c}
\hline \multirow{2}{*}{ Ano } & \multicolumn{7}{c}{ SINOP } \\
\cline { 2 - 7 } & $\begin{array}{c}\text { Ranking } \\
\text { IDHM no } \\
\text { BRASIL }\end{array}$ & $\begin{array}{c}\text { Ranking } \\
\text { IDHM no } \\
\text { Estado }\end{array}$ & IDHM & \multicolumn{3}{c}{ Dimensões do IDHM } \\
\cline { 3 - 7 } & $780^{\circ}$ & $7^{\mathbf{0}}$ & 0,500 & 0,689 & 0,780 & 0,232 \\
\hline 1991 & $1069^{\circ}$ & $13^{\circ}$ & 0,626 & 0,713 & 0,802 & 0,430 \\
\hline 2000 & $467^{\circ}$ & $5^{\circ}$ & 0,754 & 0,755 & 0,832 & 0,682 \\
\hline 2010 & Ano & $\begin{array}{c}\text { Posicionamento Ranking } \\
\text { em relação ano anterior }\end{array}$ & \multicolumn{2}{|c}{ Evolução Percentual em relação ano anterior } \\
\hline 2000 & -289 & -6 & $25,2 \%$ & $3,5 \%$ & $2,8 \%$ & $85,3 \%$ \\
\hline 2010 & 602 & 8 & $20,4 \%$ & $5,9 \%$ & $3,7 \%$ & $58,6 \%$ \\
\hline
\end{tabular}

Fonte: Elaborado pelos autores com base nos dados de ATLASBR (2020). 
Legenda:

\begin{tabular}{|l|l|}
\hline \multicolumn{1}{|c|}{ IDHM } & Conceitos \\
\hline $0,0-0,499$ & Muito Baixo \\
\hline $0,500-0,599$ & Baixo \\
\hline $0,600-0,699$ & Médio \\
\hline $0,700-0,799$ & Alto \\
\hline $0,800-1,0$ & Muito Alto \\
\hline
\end{tabular}

Como se pode observar o IDHM da Educação nos anos e 1991 e 2000 apresenta o conceito "muito baixo", mesmo com uma evolução de 85,3\% verificada no ano de 2000 em relação ao ano anterior, permaneceu com aquele conceito muito baixo, contudo em 2010 a evolução percentual de 58,6\% em relação ao ano anterior alterou o da dimensão conceito para "médio", representando assim uma significativa evolução, responsável inclusive pela melhora do IDHM do município, uma vez que os IDHMs das dimensões da Renda e Longevidade apresentaram uma evolução percentual muito menor do que aquela verificada na dimensão da Educação.

A Tabela 2 apresenta o percentual de afastamento do IDHM de Sinop do topo do ranking do IDHM, como mencionado o valor de 1,0 representa a máximo que se pode obter. Assim sendo, quanto menor o valor percentual resultante nesta comparação, maior será a proximidade da dimensão do IDHM tratada com o topo do indicador.

Tabela 2 - Percentual de afastamento do IDHM Sinop em relação a 1,0

\begin{tabular}{c|c|c|c|c}
\hline \multicolumn{5}{|c}{ Sinop } \\
\hline \multirow{2}{*}{ Ano } & \multirow{2}{*}{ IDHM } & \multicolumn{3}{c}{ Dimensões do IDHM } \\
\cline { 3 - 5 } & & Renda & Longevidade & Educação \\
\hline 1991 & $50,0 \%$ & $31,1 \%$ & $22,0 \%$ & $76,8 \%$ \\
\hline 2000 & $37,4 \%$ & $28,7 \%$ & $19,8 \%$ & $57,0 \%$ \\
\hline 2010 & $24,6 \%$ & $24,5 \%$ & $16,8 \%$ & $31,8 \%$ \\
\hline
\end{tabular}

Verifica-se na Tabela 2 que no ano de 1991 o IDHM de Sinop se posicionava na metade do intervalo considerado pelo índice. Ainda neste mesmo ano, ao se verificar os indicadores por dimensão, o que possuía maior afastamento era o da Educação e, pela magnitude deste afastamento $(76,8 \%)$ pode-se inferir a condição precária nesta dimensão à época.

Já no ano de 2000 houve uma melhora tanto no IDHM do Município quanto nos indicadores por dimensão, cabendo mencionar que a dimensão da Educação foi aquela que apresentou a melhor evolução, contundo ainda em situação precária, uma vez que o percentual de afastamento ainda refletia que se encontrava abaixo da média do indicador. A mesma situação de evolução voltou a se repetir na década seguinte em 2010, com os melhores resultados para a Educação.

Para que se tenha uma dimensão do comportamento do IDHM de Sinop em relação ao IDHM do Estado, a Tabela 3 apresenta o IDHM do Estado de Mato Grosso.

Tabela 3 - IDHM do Estado de Mato Grosso

\author{
Mato Grosso
}


EVOLUÇÃO DO ÍNDICE DE DESENVOLVIMENTO HUMANO - IDHM DE SINOP: UMA ANÁLISE A PARTIR DA DIMENSÃO DA EDUCAÇÃO NO MUNICÍPIO

\begin{tabular}{c|c|c|c|c}
\hline Ranking & \multirow{2}{*}{$\begin{array}{c}\text { IDHM } \\
\text { IDHM }\end{array}$} & \multicolumn{3}{|c}{ Dimensões do IDHM } \\
\cline { 3 - 5 } BRASIL & Grosso & Renda & Longevidade & Educação \\
\hline $13^{\circ}$ & 0,449 & 0,654 & 0,627 & 0,221 \\
\hline $10^{\circ}$ & 0,601 & 0,740 & 0,689 & 0,426 \\
\hline $11^{\mathbf{o}}$ & 0,725 & 0,821 & 0,732 & 0,635 \\
\hline
\end{tabular}

Fonte: Elaborado pelos autores com base nos dados de ATLASBR (2020).

Legenda:

\begin{tabular}{|l|l|}
\hline \multicolumn{1}{|c|}{ IDHM } & Conceitos \\
\hline $0,0-0,499$ & Muito Baixo \\
\hline $0,500-0,599$ & Baixo \\
\hline $0,600-0,699$ & Médio \\
\hline $0,700-0,799$ & Alto \\
\hline $0,800-1,0$ & Muito Alto \\
\hline
\end{tabular}

Em relação ao Estado de Mato Grosso, Sinop possui somente dois valores de IDHM menores, estão eles na dimensão Renda nos anos de 2000 e 2010. Assim sendo, pode se concluir que Sinop possui um bom desempenho no Estado, haja vista seu posicionamento na $7^{\mathrm{a}}, 13^{\mathrm{a}}$ e $5^{\mathrm{a}}$ posição nos rankings de 1991, 2000 e 2010 respectivamente, cabendo lembrar que o Estado possui um total de 141 municípios.

\subsection{Panorama do Ensino Fundamental e Ensino Médio em Sinop}

A Tabela 4 apresenta a taxa de analfabetismo por faixa etária, comparando-se o País, o Estado e o Município.

Tabela 4 - Taxa de analfabetismo nas faixas de idade de 11 a 14 e de 25 anos ou mais

\begin{tabular}{l|c|c|c|c|c|c}
\hline \multirow{2}{*}{ Territorialidades } & \multicolumn{3}{|c|}{$\begin{array}{c}\text { Taxa de analfabetismo - 11 a } \\
\mathbf{1 4} \text { anos de idade }\end{array}$} & \multicolumn{2}{c}{$\begin{array}{c}\text { Taxa de analfabetismo - 25 } \\
\text { anos ou mais de idade }\end{array}$} \\
\cline { 2 - 7 } & $\mathbf{1 9 9 1}$ & $\mathbf{2 0 0 0}$ & $\mathbf{2 0 1 0}$ & $\mathbf{1 9 9 1}$ & $\mathbf{2 0 0 0}$ & $\mathbf{2 0 1 0}$ \\
\hline Brasil & 16,08 & 6,26 & 3,24 & 23,45 & 16,75 & 11,82 \\
\hline Mato Grosso & 9,51 & 2,68 & 2,00 & 24,88 & 16,33 & 10,82 \\
\hline Sinop (MT) & 5,17 & 1,44 & 1,24 & 14,45 & 11,25 & 6,62 \\
\hline
\end{tabular}

Fonte: Elaborado pelos autores com base nos dados de ATLASBR (2020).

Registre-se a dramaticidade que as altas taxas de analfabetismo representam para uma sociedade no que se refere a qualidade de vida da população.

$\mathrm{Na}$ Tabela 5 verifica-se que em todos os períodos de tempo mencionados e em todas as faixas de idade, o município de Sinop apresenta as menores taxas de analfabetismo quando comparadas ao Estado de Mato Grosso e ao País.

Tabela 5 - Percentual da população com Ensino Médio completo nas faixas de idade de 18 a 20 e de 25 anos ou mais no Brasil, Mato Grosso e Sinop

\begin{tabular}{l|c|c|c|c|c|c}
\hline \multirow{2}{*}{ Territorialidades } & \multicolumn{3}{|c|}{$\begin{array}{c}\text { \% de } 18 \text { a } 20 \text { anos de idade com } \\
\text { Ensino Médio completo }\end{array}$} & \multicolumn{2}{|c}{$\begin{array}{c}\% \text { de } 25 \text { anos ou mais de idade } \\
\text { com Ensino Médio completo }\end{array}$} \\
\cline { 2 - 7 } & 1991 & 2000 & 2010 & 1991 & 2000 & 2010 \\
\hline
\end{tabular}


EVOLUÇÃO DO ÍNDICE DE DESENVOLVIMENTO HUMANO - IDHM DE SINOP: UMA ANÁLISE A PARTIR DA DIMENSÃO DA EDUCAÇÃO NO MUNICÍPIO

\begin{tabular}{l|c|c|c|c|c|c}
\hline Brasil & 12,98 & 24,82 & 41,01 & 17,94 & 23,51 & 35,83 \\
\hline Mato Grosso & 8,36 & 22,53 & 42,36 & 13,58 & 20,01 & 33,03 \\
\hline Sinop (MT) & 5,96 & 17,87 & 49,64 & 12,05 & 18,24 & 35,48 \\
\hline
\end{tabular}

Analisando-se os percentuais acima mostrados na Tabela 5, observa-se que Sinop não apresentou bom desempenho em nenhuma modalidade, em nenhum dos anos analisados, tendo apenas melhorado no ano de 2010, mas carecendo ainda de melhores percentuais.

Tabela 6 - Percentual da população com Ensino Fundamental completo nas faixas de idade de 15 a 17 e de 25 anos ou mais no Brasil, Mato Grosso e Sinop

\begin{tabular}{l|c|c|c|c|c|c}
\hline \multirow{2}{*}{ Territorialidades } & \multicolumn{3}{|c|}{$\begin{array}{c}\text { \% de 15 a 17 anos de idade com } \\
\text { Ensino Fundamental completo }\end{array}$} & $\begin{array}{c}\text { \% de 18 anos ou mais de idade } \\
\text { com Ensino Fundamental } \\
\text { completo }\end{array}$ \\
\cline { 2 - 7 } & $\mathbf{1 9 9 1}$ & $\mathbf{2 0 0 0}$ & $\mathbf{2 0 1 0}$ & $\mathbf{1 9 9 1}$ & $\mathbf{2 0 0 0}$ & $\mathbf{2 0 1 0}$ \\
\hline Brasil & 20,01 & 39,72 & 57,24 & 30,09 & 39,76 & 54,92 \\
\hline Mato Grosso & 15,68 & 37,66 & 62,17 & 24,76 & 35,82 & 53,20 \\
\hline Sinop (MT) & 23,34 & 40,44 & 72,00 & 23,22 & 34,40 & 57,14 \\
\hline
\end{tabular}

Fonte: Elaborado pelos autores com base nos dados de ATLASBR (2020).

Quando analisados os percentuais da população com Ensino Fundamental completo, considerando-se as faixas etárias de 15 a 17 e de 25 anos ou mais, Sinop desponta no ano de 2010 nos dois segmentos analisados, tanto em relação ao Estado, quanto em relação ao País.

Tabela 7 - Expectativa de anos de estudo aos 18 anos de idade no Brasil, Mato Grosso e Sinop

\begin{tabular}{l|c|c|c}
\hline \multirow{2}{*}{ Territorialidades } & \multicolumn{3}{|c}{$\begin{array}{c}\text { Expectativa de anos de estudo } \\
\text { aos } \mathbf{1 8} \text { anos de idade }\end{array}$} \\
\cline { 2 - 4 } & $\mathbf{1 9 9 1}$ & $\mathbf{2 0 0 0}$ & $\mathbf{2 0 1 0}$ \\
\hline Brasil & 8,16 & 8,76 & 9,54 \\
\hline Mato Grosso & 8,16 & 9,02 & 9,29 \\
\hline Sinop (MT) & 9,11 & 9,13 & 10,52 \\
\hline \multicolumn{3}{r}{ Fonte: ATLASBR (2020). }
\end{tabular}

A expectativa de anos de estudo aos 18 anos apresentou-se melhor em Sinop, em comparação ao Estado de Mato Grosso e ao País, nos três anos analisados.

\subsection{Panorama do Ensino Superior em Sinop}

Consultadas as bases de dados do INEP, a Tabela 8 apresenta o número de Instituições de Ensino Superior no município de Sinop, considerando-se o intervalo de tempo compreendido entre 2009 e 2017, anos em que o Censo do Ensino Superior foi realizado e está disponibilizado na Base de Dados INEP para consulta por meio do INEPDATA.

Tabela 8 - Número de Instituições de Educação Superior em Sinop no período de 2009 a 2017

\begin{tabular}{c|c}
\hline $\begin{array}{c}\text { Ano Censo do } \\
\text { Ensino Superior } \\
\text { INEP }\end{array}$ & $\begin{array}{c}\text { Número de Instituições de } \\
\text { Educação Superior em Sinop }\end{array}$ \\
\hline 2009 & 5 \\
\hline 2010 & 5 \\
\hline 2011 & 4 \\
\hline
\end{tabular}


EVOLUÇÃO DO ÍNDICE DE DESENVOLVIMENTO HUMANO - IDHM DE SINOP: UMA ANÁLISE A PARTIR DA DIMENSÃO DA EDUCAÇÃO NO MUNICÍPIO

\begin{tabular}{l|l}
\hline 2012 & 5 \\
\hline 2013 & 5 \\
\hline 2014 & 5 \\
\hline 2015 & 5 \\
\hline 2016 & 5 \\
\hline 2017 & 4 \\
\hline
\end{tabular}

Fonte: MEC/Inep/Deed - INEPDATA (2020).

A Tabela 8 apresenta as Instituições de Educação Superior (IES) em atividade no município de Sinop com abrangência geográfica do endereço da reitoria ou sede administrativa da IES, desta forma não estão computadas nesta tabela a Universidade Federal de Mato Grosso (campus Sinop) e a Universidade Estadual de Mato Grosso (unidade regionalizada) que atuam no município desde os anos de 1981 e 1990, respectivamente. Assim sendo, os números apresentados se referem as instituições privadas somente.

Consultada a base de dados do ensino superior brasileiro no município de Sinop, por meio da base de dados E-MEC foram obtidas as seguintes informações relacionadas ao ensino superior apresentadas de forma sumarizada. Foram computadas por modalidade de ensino, presencial e a distância.

Somente forem consideradas nos dados apresentado as IES com status "em funcionamento" no campo "Situação" e com informação de data no campo "Data início funcionamento". Dessa forma, somente contam das tabelas apresentadas as instituições em atividade. Os dados relativos a cada IES estão apresentados por categoria administrativa, nome dos cursos, grau acadêmico e vagas autorizadas, conforme Tabela 9.

Tabela 9 - IES em 2020 ativas em Sinop na modalidade de ensino presencial

\begin{tabular}{|c|c|c|c|c|}
\hline Instituição (IES) - Sigla & $\begin{array}{l}\text { Categoria } \\
\text { Adm. }\end{array}$ & Nome do Curso & $\begin{array}{c}\text { Grau } \\
\text { Acadêmico }\end{array}$ & $\begin{array}{c}\text { Vagas } \\
\text { Autorizadas }\end{array}$ \\
\hline \multirow{2}{*}{$\begin{array}{l}\text { Universidade Federal de } \\
\text { Mato Grosso - UFMT }\end{array}$} & \multirow{2}{*}{$\begin{array}{l}\text { Pública } \\
\text { Federal }\end{array}$} & $\begin{array}{l}\text { Ciências Naturais e Matemática - Física, } \\
\text { Ciências Naturais e Matemática - Matemática; } \\
\text { Ciências Naturais e Matemática - Química }\end{array}$ & Licenciatura & 171 \\
\hline & & $\begin{array}{l}\text { Agronomia; Enfermagem; Engenharia } \\
\text { Florestal; Medicina Veterinária; Zootecnia; } \\
\text { Engenharia Agrícola e Ambiental; Farmácia; } \\
\text { Medicina }\end{array}$ & Bacharelado & 670 \\
\hline \multirow{2}{*}{$\begin{array}{l}\text { Universidade do Estado de } \\
\text { Mato Grosso Carlos } \\
\text { Alberto Reyes Maldonado } \\
\text { - UNEMAT }\end{array}$} & \multirow{2}{*}{$\begin{array}{l}\text { Pública } \\
\text { Estadual }\end{array}$} & $\begin{array}{l}\text { Letras - Português e Inglês; Matemática; } \\
\text { Pedagogia; Geografia; Computação e } \\
\text { Informática }\end{array}$ & Licenciatura & 420 \\
\hline & & $\begin{array}{l}\text { Ciências Contábeis, Administração, Ciência } \\
\text { Econômicas, Engenharia Civil, Engenharia } \\
\text { Elétrica, Sistemas de Informação }\end{array}$ & Bacharelado & 540 \\
\hline \multirow{2}{*}{$\begin{array}{l}\text { Faculdade de Ciências } \\
\text { Jurídicas, Gerenciais e } \\
\text { Educação de Sinop }\end{array}$} & \multirow{2}{*}{$\begin{array}{l}\text { Privada } \\
\text { com fins } \\
\text { lucrativos }\end{array}$} & Administração, Ciências Contábeis, Direito & Bacharelado & 450 \\
\hline & & Redes de Computadores & Tecnológico & 100 \\
\hline \multirow{2}{*}{ Faculdade Sinop - FASIP } & \multirow{2}{*}{$\begin{array}{l}\text { Privada } \\
\text { com fins } \\
\text { lucrativos }\end{array}$} & Administração, Direito & Bacharelado & 400 \\
\hline & & Gastronomia & Tecnológico & 150 \\
\hline $\begin{array}{l}\text { Faculdade de Ciências } \\
\text { Sociais Aplicadas de } \\
\text { Sinop - FACISAS }\end{array}$ & $\begin{array}{l}\text { Privada } \\
\text { com fins } \\
\text { lucrativos }\end{array}$ & 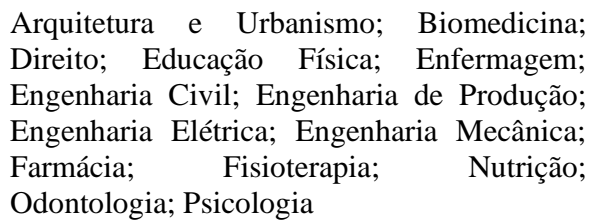 & Bacharelado & 1.785 \\
\hline
\end{tabular}


EVOLUÇÃO DO ÍNDICE DE DESENVOLVIMENTO HUMANO - IDHM DE SINOP: UMA ANÁLISE A PARTIR DA DIMENSÃO DA EDUCAÇÃO NO MUNICÍPIO

\begin{tabular}{|c|c|c|c|c|}
\hline & & Estética e Cosmética; Gastronomia & Tecnológico & 180 \\
\hline \multirow[t]{3}{*}{$\begin{array}{l}\text { Centro } \\
\text { FASIPE }\end{array}$} & \multirow[t]{3}{*}{$\begin{array}{l}\text { Privada } \\
\text { com fins } \\
\text { lucrativos }\end{array}$} & $\begin{array}{l}\text { Agronomia; Arquitetura e } \\
\text { Biomedicina; Crbanismo; } \\
\text { Comunicação Social - Jornalismo; Educaçãão } \\
\text { Contábeis; } \\
\text { Física; Enfermagem; Engenharia Civil; } \\
\text { Engenharia de Produção; Estética e } \\
\text { Cosmética; Farmácia; Fisioterapia; Nutrição; } \\
\text { Odontologia; Psicologia }\end{array}$ & Bacharelado & 2.175 \\
\hline & & Educação Física & Licenciatura & 200 \\
\hline & & $\begin{array}{l}\text { Análise e Desenvolvimento de Sistemas; } \\
\text { Radiologia }\end{array}$ & Tecnológico & 300 \\
\hline \multirow{2}{*}{$\begin{array}{l}\text { Faculdade de Tecnologia } \\
\text { de Sinop - FASTECH }\end{array}$} & \multirow{2}{*}{$\begin{array}{l}\text { Privada } \\
\text { com fins } \\
\text { lucrativos }\end{array}$} & $\begin{array}{l}\text { Engenharia de Alimentos, Engenharia de } \\
\text { Produção }\end{array}$ & Bacharelado & 100 \\
\hline & & Estética e Cosmética & Tecnológico & 50 \\
\hline \multicolumn{4}{|c|}{ Total de Vagas Oferecidas no Ensino Superior de Sinop em 2020} & 7.691 \\
\hline
\end{tabular}

Fonte: Elaborada pelos autores a partir das informações E-MEC (2020).

Pode-se observar que as instituições públicas com 1.801 vagas autorizadas, respondem por $23,4 \%$ das vagas enquanto as instituições privadas com 5.890 vagas respondem por $76,6 \%$, concentrando assim o maior número de possibilidades para a frequência no ensino superior no município. Verifica-se ainda que somente as instituições privadas atuam com cursos tecnológicos com 780 vagas o que representa $10,1 \%$ do total de cursos ofertados.

No que se refere ao Ensino Superior à Distância em Sinop, todas as IES que oferecem cursos nesta modalidade estão na Categoria Administrativa "Privada com fins lucrativos", conforme apresenta a Tabela 10.

Tabela 10 - IES em 2020 ativas em Sinop na modalidade de ensino à distância

\begin{tabular}{c|c|c|c|c|c}
\hline \multicolumn{2}{c|}{ Instituições (IES) } & \multicolumn{2}{c}{ Número de Cursos Oferecidos por Grau } \\
Acadêmico & \multirow{2}{*}{ Total } \\
\cline { 1 - 4 } $\begin{array}{c}\text { Organização } \\
\text { Acadêmica }\end{array}$ & $\begin{array}{c}\text { Quantidade de } \\
\text { IES com oferta de } \\
\text { cursos em Sinop }\end{array}$ & Bacharelado & Licenciatura & Tecnólogo & \\
\hline Universidade & 7 & 95 & 65 & 167 & 327 \\
\hline Centro Universitário & 15 & 110 & 70 & 172 & 352 \\
\hline Faculdade & 5 & 17 & 24 & 26 & 67 \\
\hline \multicolumn{7}{c|}{ Total } & $\mathbf{2 7}$ & $\mathbf{2 2 2}$ & $\mathbf{1 5 9}$ & $\mathbf{3 6 5}$ & $\mathbf{7 4 6}$ \\
\hline
\end{tabular}

Com o objetivo de ressaltar o número de possibilidades que esta modalidade de ensino representa, optou-se por apresentar de forma sintetizada a quantidade de IES que oferecem cursos na modalidade a distância por grau acadêmico oferecido. Não cabe nesta análise a apresentação do número de vagas autorizadas, a exemplo do que correu com a modalidade presencial, uma vez que a autorização das vagas nem sempre está relacionada ao polo específico.

A Tabela 11 apresenta a quantidade de cursos EAD iniciados no período de 2003 a 2020.

Tabela 11 - Número de Cursos EAD iniciados no período de 2003 a 2020 
EVOLUÇÃO DO ÍNDICE DE DESENVOLVIMENTO HUMANO - IDHM DE SINOP: UMA ANÁLISE A PARTIR DA DIMENSÃO DA EDUCAÇÃO NO MUNICÍPIO

\begin{tabular}{c|c}
\hline $\begin{array}{c}\text { Data de Início dos } \\
\text { Cursos }\end{array}$ & $\begin{array}{c}\text { Número de Cursos } \\
\text { Iniciados }\end{array}$ \\
\hline 2003 & 1 \\
\hline 2004 & 3 \\
\hline 2005 & 7 \\
\hline 2006 & 31 \\
\hline 2007 & 18 \\
\hline 2008 & 21 \\
\hline 2009 & 12 \\
\hline 2010 & 12 \\
\hline 2011 & 11 \\
\hline 2012 & 19 \\
\hline 2013 & 20 \\
\hline 2014 & 47 \\
\hline 2015 & 43 \\
\hline 2016 & 52 \\
\hline 2017 & 69 \\
\hline 2018 & 128 \\
\hline 2019 & 160 \\
\hline 2020 & 67 \\
\hline Não iniciados & 25 \\
\hline Total & $\mathbf{7 4 6}$ \\
\hline
\end{tabular}

Fonte: Elaborada pelos autores a partir das informações E-MEC (2020).

A expansão no número de cursos ofertados se mostrou crescente ao longo desse período podendo-se observar um crescimento acentuado nos anos de 2018 e 2019. Embora não se possa estabelecer uma relação direta entre o número de cursos oferecidos com aqueles que de fato possuem alunos nele matriculados, inegável é a possibilidade de formação das pessoas no município de Sinop frente as diversas alternativas de estudo nesse nível de educação e modalidade lá ofertadas.

Inegável que frente a essas possibilidades de formação criadas pelo ensino à distância, cabe destacar as condições mencionadas por Rosini (2007) quanto a influência das tecnologias de informação que necessariamente devem estar presentes nas regiões em que esta modalidade é oferecida, assim como, o papel includente que representa para a população no ensino superior.

A Tabela 12 mostra o número de alunos matriculados no Ensino Superior em Sinop 2017 e apresenta a distribuição dos alunos Matriculados por categoria de instituição, pública e privada e por modalidade de Ensino.

Tabela 12 - Número de Alunos Matriculados no Ensino Superior em Sinop 2017

\begin{tabular}{l|r|r|r|r|r|r}
\hline \multirow{2}{*}{ Modalidade de Ensino } & \multicolumn{3}{|c|}{ Número de Alunos Matriculados no Ensino Superior em } & \multirow{2}{*}{ Total } \\
\cline { 2 - 6 } & \multicolumn{2}{|c|}{ PÚBLICA } & \multirow{2}{*}{ Total } & \multirow{2}{*}{ PRIVADA } & \multirow{2}{*}{ Total } & \\
\cline { 2 - 6 } & FEDERAL & ESTADUAL & & & & \\
\hline Presencial & 2.498 & 2.574 & 5.072 & 7.720 & 7.720 & $\mathbf{1 2 . 7 9 2}$ \\
\hline A Distância & 0 & 0 & 0 & 2.007 & 2.007 & $\mathbf{2 . 0 0 7}$ \\
\hline Total & $\mathbf{2 . 4 9 8}$ & $\mathbf{2 . 5 7 4}$ & $\mathbf{5 . 0 7 2}$ & $\mathbf{9 . 7 2 7}$ & $\mathbf{9 . 7 2 7}$ & $\mathbf{1 4 . 7 9 9}$ \\
\hline
\end{tabular}

Fonte: Elaborada pelos autores a partir das informações INEPDATA (2020). 


\section{EVOLUÇÃO DO ÍNDICE DE DESENVOLVIMENTO HUMANO - IDHM DE SINOP: UMA ANÁLISE A PARTIR DA DIMENSÃO DA EDUCAÇÃO NO MUNICÍPIO}

Observa se que no ano de 2017 as IES públicas não atuavam com a modalidade de Ensino à Distância, enquanto as privadas possuíam 20,6\% de seus alunos matriculados nesta modalidade de ensino, o que representou $13,6 \%$ dos alunos totais matriculados naquele ano.

Por sua vez, a Tabela 13 apresenta o número de alunos concluintes, ingressantes e matriculados no Ensino Superior em Sinop, considerando-se o período de 2009 a 2017 em todas as modalidades de ensino, presencial e a distância, apresenta o total de alunos.

Tabela 13 - Número de Alunos Concluintes, ingressantes e matriculados no Ensino Superior em Sinop no período de 2009 a 2017

\begin{tabular}{c|c|c|c|c|c|c|c|c|c}
\hline \multirow{2}{*}{$\begin{array}{c}\text { Ano } \\
\begin{array}{c}\text { Censo } \\
\text { INEP }\end{array}\end{array}$} & \multicolumn{3}{|c|}{ Concluintes } & \multicolumn{3}{c|}{ Ingressantes } & \multicolumn{3}{c}{ Matriculados } \\
\cline { 2 - 10 } & Pública & Privada & Total & Pública & Privada & Total & Pública & Privada & Total \\
\hline 2009 & 270 & 350 & $\mathbf{6 2 0}$ & 1.405 & 1.338 & $\mathbf{2 . 7 4 3}$ & 4.645 & 4.153 & $\mathbf{8 . 7 9 8}$ \\
\hline 2010 & 307 & 527 & $\mathbf{8 3 4}$ & 0 & 385 & $\mathbf{3 8 5}$ & 4.468 & 5.045 & $\mathbf{9 . 5 1 3}$ \\
\hline 2011 & 482 & 964 & $\mathbf{1 . 4 4 6}$ & 0 & 604 & $\mathbf{6 0 4}$ & 4.840 & 5.488 & $\mathbf{1 0 . 3 2 8}$ \\
\hline 2012 & 534 & 703 & $\mathbf{1 . 2 3 7}$ & 1.250 & 3.096 & $\mathbf{4 . 3 4 6}$ & 4.688 & 6.300 & $\mathbf{1 0 . 9 8 8}$ \\
\hline 2013 & 524 & 782 & $\mathbf{1 . 3 0 6}$ & 1.274 & 3.278 & $\mathbf{4 . 5 5 2}$ & 4.681 & 7.532 & $\mathbf{1 2 . 2 1 3}$ \\
\hline 2014 & 631 & 966 & $\mathbf{1 . 5 9 7}$ & 1.260 & 3.933 & $\mathbf{5 . 1 9 3}$ & 4.797 & 8.921 & $\mathbf{1 3 . 7 1 8}$ \\
\hline 2015 & 683 & 1.015 & $\mathbf{1 . 6 9 8}$ & 2.073 & 3.392 & $\mathbf{5 . 4 6 5}$ & 4.646 & 9.525 & $\mathbf{1 4 . 1 7 1}$ \\
\hline 2016 & 521 & 1.260 & $\mathbf{1 . 7 8 1}$ & 2.699 & 3.662 & $\mathbf{6 . 3 6 1}$ & 4.733 & 9.881 & $\mathbf{1 4 . 6 1 4}$ \\
\hline 2017 & 491 & 1.426 & $\mathbf{1 . 9 1 7}$ & 1.499 & 3.643 & $\mathbf{5 . 1 4 2}$ & 5.072 & 9.727 & $\mathbf{1 4 . 7 9 9}$ \\
\hline
\end{tabular}

Fonte: Elaborada pelos autores a partir das informações INEPDATA (2020).

Pode se observar o crescimento da população universitária ao longo dos anos no período apresentado nas três categorias. Tomando como base o ano de 2009 e o ano de 2017 verifica se ao longo desse período de tempo um crescimento de $209,2 \%$ nos alunos concluintes, $87,5 \%$ nos ingressantes e $68,2 \%$ nos matriculados, sendo que o sistema privado mais do que dobrou o número de alunos em todas as categorias.

Embora não se possa afirmar que todos os alunos sejam residentes no município e lá permaneceram após a sua formação, pode-se inferir que a expansão do ensino superior naquele município acompanhou o crescimento demográfico ocorrido possibilitando acesso a este nível de educação.

Essa situação da evolução no ensino superior pode ser identificada na Tabela 14, que mostra o percentual de 25 anos ou mais de idade com ensino superior completo.

Tabela 14 - Percentual de 25 anos ou mais de idade com ensino superior completo

\begin{tabular}{l|c|c|c}
\hline \multirow{2}{*}{ Territorialidades } & \multicolumn{3}{c}{$\begin{array}{c}\text { \% de } 25 \text { anos ou mais de idade } \\
\text { com ensino superior completo }\end{array}$} \\
\cline { 2 - 4 } & $\mathbf{1 9 9 1}$ & $\mathbf{2 0 0 0}$ & $\mathbf{2 0 1 0}$ \\
\hline Brasil & 5,75 & 6,77 & 11,27 \\
\hline Mato Grosso & 3,97 & 5,09 & 10,47 \\
\hline Sinop (MT) & 3,26 & 4,48 & 11,19 \\
\hline
\end{tabular}

Fonte: ATLASBR (2020).

Verifica-se que em todos os anos apresentados Sinop apresenta os menores percentuais em relação ao Estado de Mato Grosso e do Brasil, contudo deve-se observar que o percentual 


\section{EVOLUÇÃO DO ÍNDICE DE DESENVOLVIMENTO HUMANO - IDHM DE SINOP: UMA ANÁLISE A PARTIR DA DIMENSÃO DA EDUCAÇÃO NO MUNICÍPIO}

apresenta uma evolução em 2000 em relação a 1991 e em 2010 em relação a 2000, este último com uma melhora significativa capaz de colocar Sinop em uma condição melhor que o Estado e deixá-la muito próxima do indicador do país.

Não foram levantados dados da oferta de cursos de pós-graduação lato sensu e número de alunos neles matriculados, embora sejam ofertados pelas IES da região. Optou-se por identificar somente dados referentes a pós-graduação stricto sensu pelo fato da proposta que esta modalidade de ensino proporciona, em especial a formação de pesquisadores e profissionais para atuar no ensino superior.

Naturalmente cabe ressaltar a contribuição destes cursos na formação dos professores que atuam no ensino fundamental e médio auxiliando assim no cumprimento das metas estabelecidas no Plano Nacional de Educação - PNE 2014-2024, no que se refere a qualificação dos docentes que atuam naqueles níveis de ensino. Embora esta categoria de cursos não esteja presente dentre os quesitos avaliados para a composição do IDHM, vale reconhecer a sua importância no contexto educacional.

Consultada a base da CAPES de Cursos Avaliados e Reconhecidos no Município de Sinop, verificou-se a existência de dois cursos de pós-graduação stricto sensu, mestrado acadêmico, em Ciências Ambientais; e Zootecnia ambos oferecidos pela Universidade Federal de Mato Grosso (UFMT) em Sinop (PLATAFORMA SUCUPIRA, 2020).

Adicionalmente, as possibilidades locais de se realizar um curso de pós-graduação stricto sensu em Sinop a Tabela 15 traz a totalização desses cursos em Mato Grosso e apresenta o número de cursos disponíveis.

Tabela 15 - Totais de Cursos de Pós-graduação Stricto Sensu no Estado de Mato Grosso

Totais de Cursos de Pós-graduação Stricto Sensu no Estado de Mato Grosso

\begin{tabular}{l|c|c|c|c|c}
\hline \multicolumn{1}{c|}{ Instituição de Ensino } & Total & $\begin{array}{c}\text { Mestrado } \\
\text { Acadêmico }\end{array}$ & $\begin{array}{c}\text { Doutorado } \\
\text { Acadêmico }\end{array}$ & $\begin{array}{c}\text { Mestrado } \\
\text { Profissional }\end{array}$ & $\begin{array}{c}\text { Doutorado } \\
\text { Profissional }\end{array}$ \\
\hline $\begin{array}{l}\text { Centro Universitário de Várzea Grande } \\
\text { (UNIVAG) }\end{array}$ & 1 & 1 & 0 & 0 & 0 \\
\hline $\begin{array}{l}\text { Hospital Universitário Júlio Müller - } \\
\text { Ebserh (HUJM) }\end{array}$ & 1 & 0 & 0 & 1 & 0 \\
\hline $\begin{array}{l}\text { Instituto Federal de Educação Ciência e } \\
\text { Tecnologia de Mato Grosso (IFMT) }\end{array}$ & 2 & 1 & 0 & 1 & 0 \\
\hline $\begin{array}{l}\text { Universidade de Cuiabá (UNIC) } \\
\text { Totais }\end{array}$ & 7 & 5 & 2 & 0 & 0 \\
\hline $\begin{array}{l}\text { Universidade do Estado de Mato Grosso } \\
\text { (UNEMAT) }\end{array}$ & 16 & 11 & 4 & 1 & 0 \\
\hline $\begin{array}{l}\text { Universidade Federal de Mato Grosso } \\
\text { (UFMT) }\end{array}$ & 58 & 42 & 14 & 2 & 0 \\
\hline
\end{tabular}

Fonte: Plataforma Sucupira (2020).

Observa-se uma concentração da oferta de cursos nas instituições públicas UFMT e UNEMAT, ambas localizadas no Estado, fato que seguramente se deve ao tempo que estas instituições estão presentes em Mato Grosso

Considerando-se a abrangente e detalhada análise dos dados sobre Educação no município de Sinop, coletados em documentos produzidos por órgãos oficiais, percebe-se REPAE, São Paulo, v. 6, n. 2, p. 127-154, jul./dez. 2020. ISSN: 2447-6129 


\section{EVOLUÇÃO DO ÍNDICE DE DESENVOLVIMENTO HUMANO - IDHM DE SINOP: UMA ANÁLISE A PARTIR DA DIMENSÃO DA EDUCAÇÃO NO MUNICÍPIO}

consonância com os teóricos (SEN, 2000; RAVACHE, 2013, BELLINGIERI, 2017; SOUZA, 2017; AVELAR, SILVA-OLIVEIRA E PEREIRA, 2019; GIOVANINI, 2020; MELATI E JANISSEK-MUNIZ, 2020; SANTOS, A. ET AL., 2020; SANTOS, I. ET AL., 2020) em relação às contribuições que essa dimensão Educação pode dar para o desenvolvimento local e regional.

\section{CONCLUSÕES E RECOMENDAÇÕES}

A utilização de indicadores e métricas de desenvolvimento humano já existentes e consolidadas quanto a sua metodologia e significado são imprescindíveis nos estudos acadêmicos. A sua aplicação e análise contribuem fortemente para que sejam identificadas as relações de causa e efeito nos fenômenos estudados assim como os seus determinantes.

Neste sentido, a utilização do IDHM possibilitou uma análise detalhada de todo o cenário e contexto que envolveu o município de Sinop, no Estado de Mato Grosso, no período estudado, em especial na dimensão da Educação, em todos os seus níveis.

Atingiu-se o objetivo proposto de analisar o comportamento do IDHM do município de Sinop, é identificar no indicador Educação no IDHM de Sinop nos anos de 1991, 2000 e 2010, os fatores determinantes de sua evolução.

O grande desafio no campo da ciência na atualidade reside na necessidade da integração dos saberes das diversas áreas do conhecimento humano. Via de regra, um determinado objeto, fato ou ocorrência não pode e não deve ser tratado apenas por uma ótica de uma área do conhecimento, sob o risco de uma observação míope e que não poderá de fato revelar a verdade sobre ele, verdade esta que representa condição objetiva de sua busca no campo científico.

Nesse sentido, a proposta deste trabalho ao analisar o município de Sinop, no Estado de Mato Grosso, a partir da perspectiva do Índice de Desenvolvimento Humano Municipal IDHM, sob a dimensão da Educação pode constatar que não se tratava apenas de comparações numéricas relacionadas a evolução do seu IDHM, foram identificadas de fato, melhorias do Desenvolvimento Humano daquele município por meio da crescente participação dos residentes no sistema educacional relacionado ao ensino fundamental e médio, assim como foram observadas melhoras do indicador nas dimensões da Renda e Longevidade.

Sem o risco de incorrer em uma análise reducionista, sobre o fato da evolução do indicador da dimensão da Educação, é possível afirmar que ele é o grande responsável pela melhora do IDHM do município, contudo não podem ser ignoradas as demais dimensões neste processo, uma vez que também contribuíram nesta melhora.

Registre-se as limitações desta pesquisa ao fato de ter analisado um dentre os três aspectos do IDHM e em apenas um município brasileiro, não permitindo, dessa forma, generalizações, mas podendo ser replicado em diversos outros municípios do País.

Recomenda-se para trabalhos futuros um aprofundamento nas análises que possam estabelecer relações e correlações entre as três dimensões do IDHM, com o propósito de nortear políticas públicas no estabelecimento de seus planos de ação.

\section{REFERÊNCIAS}


EVOLUÇÃO DO ÍNDICE DE DESENVOLVIMENTO HUMANO - IDHM DE SINOP: UMA ANÁLISE A PARTIR DA DIMENSÃO DA EDUCAÇÃO NO MUNICÍPIO

ATLASBR. Atlas do Desenvolvimento Humano no Brasil. Disponível em: http://www.idhm.org.br/. Acesso em: 06 jul. 2020.

AVELAR, A. B. A; SILVA_OLIVEIRA, K. D.; PEREIRA, R. S. Education for advancing the implementation of the Sustainable Development Goals: A systematic approach. The

International Journal of Management Education. v. 17, n. 3, p. 100322, 2019. Disponível em: https://dialnet.unirioja.es/servlet/articulo?codigo=7256304. Acesso em: 17 jun. 2020.

BELLINGIERI, J. C. Teorias do desenvolvimento regional e local. Revista de

Desenvolvimento Econômico - RDE - Ano XIX - V. 2 - N. 37 - Agosto de 2017 - Salvador, BA - p. 6 - 34. Disponível em:

https://revistas.unifacs.br/index.php/rde/article/view/4678/3228. Acesso em: 14 jul. 2020.

BRASIL. MINISTÉRIO DA EDUCAÇÃO. Sobre as áreas de Avaliação. Disponível em: https://www.gov.br/capes/pt-br/acesso-a-informacao/acoes-e-programas/avaliacao/sobre-aavaliacao/areas-avaliacao/sobre-as-areas-de-avaliacao/sobre-as-areas-de-avaliacao. Acesso em: 24 jul. 2020.

BRASIL. Ministério do Desenvolvimento Regional. Política Nacional de Desenvolvimento Regional. Atualizada pelo Decreto $\mathrm{n}^{\circ}$ 9.810, de 2019. Disponível em:

https://www.gov.br/mdr/pt-br/assuntos/desenvolvimento-regional/pndr e em:

http://www.planalto.gov.br/ccivil_03/_ato2019-2022/2019/decreto/D9810.htm. Acesso em: 26 jul. 2020.

CAPES. COORDENAÇÃO DE APERFEIÇOAMENTO DE PESSOAL DE NÍVEL

SUPERIOR. Bolsas Capes. Disponível em: https://www.gov.br/capes/pt-

br/assuntos/noticias/capes-adota-modelo-inedito-de-concessao-de-bolsas. Acesso em: 06 ago 2020.

CRESWELL, J. W. Investigação Qualitativa e Projeto de Pesquisa: Escolhendo entre Cinco Abordagens. Tradução Sandra Mallmann da Rosa. Rev. Técnica: Dirceu da Silva. 3. Ed. VitaBook file: Penso, 2014. Tradução de: Qualitative Inquiry and Research Design: Choosing Among Five Approaches. Disponível em:

http://integrada.minhabiblioteca.com.br/books/9788565848893. Acesso em: 12 ago. 2020.

FLICK, U. Uma introdução à pesquisa qualitativa. 3. ed. Porto Alegre: Bookman, 2008.

GIOVANINI, Adilson. Economia compartilhada e governança pública. Revista de Administração Pública - RAP. Rio de Janeiro 54(5):1207-1238, set. - out. 2020. DOI: http://dx.doi.org/10.1590/0034-761220190080. Disponível em: https://www.scielo.br/pdf/rap/v54n5/1982-3134-rap-54-05-1207.pdf. Acesso em: 16 jul. 2020.

IBGE. INSTITUTO BRASILEIRO DE GEOGRAFIA E ESTATÍSTICA. Cidades. 2019. Disponível em: https://cidades.ibge.gov.br/brasil/mt/Sinop/panorama. Acesso em: 05 set. 2020.

INEP. INSTITUTO NACIONAL DE ESTUDOS E PESQUISAS EDUCACIONAIS ANÍSIO TEIXEIRA. Sinopse Estatística da Educação Superior 2019. Brasília: Inep, 2020. Disponível em: http://portal.inep.gov.br/basica-censo-escolar- Sinopse. Acesso em: 08 ago. 2020.

INEP. INSTITUTO NACIONAL DE ESTUDOS E PESQUISAS EDUCACIONAIS ANÍSIO TEIXEIRA. Sistema de Avaliação da Educação Básica - SAEB. Disponível em: https://www.gov.br/inep/pt-br/centrais-de-conteudo/legislacao/saeb. Acesso em: 25 ago. 2020. 
EVOLUÇÃO DO ÍNDICE DE DESENVOLVIMENTO HUMANO - IDHM DE SINOP: UMA ANÁLISE A PARTIR DA DIMENSÃO DA EDUCAÇÃO NO MUNICÍPIO

INEPDATA. INSTITUTO NACIONAL DE ESTUDOS E PESQUISAS EDUCACIONAIS ANÍSIO TEIXEIRA. Analytics. Disponível em:

https://inepdata.inep.gov.br/analytics/saw.dll?PortalGo. Acesso em: 19 jul. 2020.

LATORRACA NETTO, A.; MOURA, E. D. de. Conectando o urbano e o Ensino

Superior: análise da cidade universitária de Sinop. Dissertação (Mestrado em Geografia)

UFMT. Disponível em: https://slideplayer.com.br/slide/3120907/. Acesso em: 17 jul. 2020.

MELATI, C.; JANISSEK-MUNIZ, R. Governo inteligente: análise de dimensões sob a perspectiva de gestores públicos. Revista de Administração Pública - RAP. Rio de Janeiro 54(3):400-415, maio - jun. 2020. DOI: http://dx.doi.org/10.1590/0034-761220190226 . Disponível em: https://www.scielo.br/pdf/rap/v54n6/pt_1982-3134-rap-54-06-1672.pdf . Acesso em: 13 ago. 2020.

ONU. ORGANIZAÇÃO DAS NAÇÕES UNIDAS. Objetivos de Desenvolvimento Sustentável. Disponível em: https://odsbrasil.gov.br/. Acesso em: 30 jun. 2020.

PLATAFORMA SUCUPIRA. Cursos avaliados e reconhecidos. Disponível em: https://sucupira.capes.gov.br/sucupira/public/consultas/coleta/programa/quantitativos/quantita tivoles.jsf?cdRegiao=5\&sgUf=MT. Acesso em: 15 ago. 2020.

PNUD. PROGRAMA DAS NAÇÕES UNIDAS PARA O DESENVOLVIMENTO. Atlas do Desenvolvimento Humano. Disponível em: http://atlasbrasil.org.br/2013/. Acesso em: 16 ago. 2020.

RAVACHE, R. L. Migração e Modernização em Cidades Médias da Amazônia Legal: Área de Abrangência da BR 163. Tese (doutorado) - Universidade de São Paulo, Faculdade de Filosofia, Letras e Ciências Humanas. 2013.

ROSINI, A. As novas tecnologias da informação e a Educação a Distância. São Paulo: Thomson Learning, 2007.

SANTOS, A. G.; PEREIRA, R. S.; PALMISANO, A.; LUCAS, E. C. Institutions of Higher Education of Open Capital Acting In Brazil: Analysis Under The Optics of Governance and Social and Environmental Responsibility. Gestão \& Regionalidade. v. 36, n. 138, 2020.

DOI: https://doi.org/10.13037/gr.vol36n108.5960. Disponível em: https://seer.uscs.edu.br/index.php/revista_gestao/article/view/5960/2950. Acesso em: 08 jun. 2020.

SANTOS, I. C. dos et al. Empreendedorismo, Inovação e Desenvolvimento Econômico das Cidades: relações diretas? Anais. ENGEMA 2020.

SEN, A. Desenvolvimento como liberdade. São Paulo: Companhia das Letras, 2000.

SINOP. História de Sinop. Disponível em: https://www.sinop.mt.gov.br/A-Cidade/Historia/. Acesso em: 27 jun. 2020.

SOUZA, E. A. Reflexões acerca da história de Sinop /MT imigração e fronteira agrícola. Revista História e Diversidade, Cáceres-MT, v. 9, n. 1, p. 96-109, 2017.

TRIVIÑOS, A. N. S. Introdução à pesquisa em ciências sociais: a pesquisa qualitativa em educação. São Paulo: Atlas, 1987.

WORLD CONFERENCE ON EDUCATION FOR ALL. Meeting Basic Learning Needs. Satisfação das necessidades básicas de aprendizagem. Jomtien, Thailand, 1990. Disponível em: https://unesdoc.unesco.org/ark:/48223/pf0000086291_por. Acesso em: 23 jun. 2020. 